\title{
Model for finding the number of honey bee colonies needed for the optimal foraging process in a specific geographical location
}

\author{
Olvija Komasilova ${ }^{1}$, Vitalijs Komasilovs ${ }^{1}$, Armands Kviesis ${ }^{1}$, Aleksejs Zacepins ${ }^{\text {Corresp. } 1}$ \\ ${ }^{1}$ Department of Computer Systems, Faculty of Information Technologies, Latvia University of Life Sciences and Technologies, Jelgava, Latvia \\ Corresponding Author: Aleksejs Zacepins \\ Email address: aleksejs.zacepins@llu.lv
}

Finding a proper location for the bee apiary is a crucial task for the beekeepers and especially for the travelling beekeepers. Normally beekeepers choose the appropriate apiary location based on their previous experience and sometimes the location may not be optimal for the bee colonies. This can be explained by different flowering periods, variation of resources at the known fields, as well as other factors. In addition it is very challenging to evaluate how many bee colonies should be placed in one geographical location for the optimal nectar foraging process. This research presents a model for finding the number of honey bee colonies needed for the optimal foraging process in the specific location, taking into account several assumptions. Authors propose to take into account potential field productivity, possible chemical contamination, surroundings of the apiary. To run the model, several steps have to be completed, starting from the selection of area of interest, conversion to polygons for further calculations, defining the roads in the selected area. As the outcome of the model number of colonies that should be placed is presented to the user. The Python language was used for the model development. Model can be extended to use additional factors and values to increase the precision of the evaluation. In addition, input from users (farmers, agricultural specialists, etc.) about external factors that can affect the number of bee colonies in the apiary can be taken into account. This work is conducted within the Horizon 2020 FET project HIVEOPOLIS (Nr.824069). 
1 Model for finding the number of honey bee colonies needed for the optimal foraging 2 process in a specific geographical location

3 Olvija Komasilova, Vitalijs Komasilovs, Armands Kviesis, Aleksejs Zacepins*

Department of Computer Systems, Faculty of Information Technologies, Latvia University of Life Sciences and Technologies, Liela iela 2, Jelgava, LV-3001, Latvia

*Corresponding author: aleksejs.zacepins@1lu.lv

8

\begin{abstract}
Finding a proper location for the bee apiary is a crucial task for the beekeepers and especially for the travelling beekeepers. Normally beekeepers choose the appropriate apiary location based on their previous experience and sometimes the location may not be optimal for the bee colonies. This can be explained by different flowering periods, variation of resources at the known fields, as well as other factors. In addition it is very challenging to evaluate how many bee colonies should be placed in one geographical location for the optimal nectar foraging process. This research presents a model for finding the number of honey bee colonies needed for the optimal foraging process in the specific location, taking into account several assumptions. Authors propose to take into account potential field productivity, possible chemical contamination, surroundings of the apiary. To run the model, several steps have to be completed, starting from the selection of area of interest, conversion to polygons for further calculations, defining the roads in the selected area. As the outcome of the model number of colonies that should be placed is presented to the user. The Python language was used for the model development. Model can be extended to use additional factors and values to increase the precision of the evaluation. In addition, input from users (farmers, agricultural specialists, etc.) about external factors that can affect the number of bee colonies in the apiary can be taken into account. This work is conducted within the Horizon 2020 FET project HIVEOPOLIS (Nr.824069).
\end{abstract}

Keywords: Smart apiary; Honey bee; Precision beekeeping; Precision Apiculture; bee colony foraging process; Hiveopolis

\title{
1. Introduction
}

The Western honey bee, Apis mellifera plays a crucial role as a pollinator worldwide (Bolshakova \& Niño, 2018). Although during the last few years honey bee populations are steady and increasing in numbers with some fluctuation, there are a number of threats responsible for honey bee health and survival (Neon et al., 2021). The decline of pollinators may have important ecological and economic impacts that could significantly affect the maintenance of wild plant diversity, crop production and human welfare (Lázaro et al., 2016).

With the help of information and communication technologies by applying constant remote monitoring of the bee colonies, it is possible to react on-time to unpredictable events within the colonies (Komasilovs et al., 2019). Precision beekeeping (sometimes called also precision apiculture) is emerging and is defined as an apiary management strategy based on the remote and real-time monitoring of individual bee colonies to minimize resource consumption and maximize the productivity of bees (Zacepins et al., 2015). One of the important management decisions for 
44

45

46

47

48

49

50

51

52

53

54

55

56

57

58

59

60

61

62

63

64

65

66

67

68

69

70

71

72

73

74

75

76

77

78

79

80

81

82

83

84

85

the beekeeper is to choose how many hives should be placed in one location for optimal foraging performance. This question is also important for the commercial beekeepers as they generally own many colonies of honey bees, and if the number of colonies at one place is excessive, the foraging competition among colonies will have a direct and negative effect on hive yield (Akratanakul, 1990). In this study the optimal foraging performance is understood as follows: optimal number of colonies placed at one geographical location (within one apiary) should be able to forage the maximal amount of potential resources available during the whole active foraging period, or when considering migrating beekeeping, during one specific blooming time..

Evaluation of the number of hives needed to be placed in a specific location usually is based on beekeepers' experience or the limited availability of physical space (Komasilova et al., 2020). Beekeepers can also be informed by the local farmers about the pollination service needed and then beekeepers can decide how many hives should be transported there. In some countries, for instance in Indonesia (Gratzer et al., 2019), migratory beekeeping is very common, and beekeepers are forced to change the apiary location very often to provide food sources for their colonies. To have more precise evaluation on the number of needed colonies there are some researches in agricultural pollination which provides guidelines for stocking honey bee colonies in a crop to maximize pollination in the most economical way (Delaplane et al., 2013). The stocking rates of colonies required can be estimated indirectly by using the pollination potential of individual foragers and extrapolating the number of foraging honey bees and colonies required to pollinate a crop (Goodwin et al., 2011). In fact, most pollination handbooks are based on recommendations of a particular number of honeybee hives per crop-cultivated area (Free, 1993). Thus, evaluation of the optimal number of bee colonies is an important question, as aspects such as in-between colony resource distribution and competition should be also considered. Competition may occur among nearby bee colonies. The area of competition is usually in a circular band with radius close to the average flight distance. As the hives become further apart, competition decreases (Esteves et al., 2010). The occurrence of imbalances between the number of bee colonies in one location and the important bee forage areas and the subsequent decline in productivity per colony has been observed (Khanbash, 2001). For example, natural colony density as determined for both Palearctic and Nearctic forests was established at 0.5 colonies per $\mathrm{km}^{2}$ (Galton, 1971; Visscher \& Seeley, 1982). Other research shows that the number of natural density is $0.11-0.14$ honey bee colonies per $\mathrm{km}^{2}$ (Oleksa, Gawroński \& Tofilski, 2013; Kohl \& Rutschmann, 2018). For sure natural honey bee colonies densities that occur naturally in forests can vary widely from biome to biome and from agroecosystem to agroecosystem. In contrast to natural colonies many recommendations for orchard pollination call for one or more two-story colonies per acre (http://treefruit.wsu.edu/orchard-management/pollination/honey-bees/). In most cases, success in beekeeping depends on the availability of sufficient bee foraging resources in terms of both quality and quantity of nectar and pollen (Addi and Bareke, 2019). Hence, beekeeping is more dependent on the existing natural resource conditions of an area than any other livestock activities (Al-Ghamdi et al., 2016).

The aim of this research is to present a developed model, which can provide support for the beekeepers in finding an optimal number of hives which could be placed in one geographical location for the effective foraging process. 
This model is based on the previous author model for the bee apiary location evaluation which is described in (Komasilova et al., 2020) but has another point of view and more sophisticated level of details.

This research is conducted within the Horizon 2020 FET programme project HIVEOPOLIS (https://www.hiveopolis.eu/). Collection of hives, technologies and humans is called Hiveopolis in our concept. HIVEOPOLIS technology will be integrated in a way that it provides a synergistic added value to the colony, to its owner and to the society in general.

\section{Materials and methods}

This section describes a proposed model development process for finding the optimal number of hives in the specific geographical location which is chosen by the beekeeper and the used parameters. The model's development process is divided into two main steps. In the first step, the aerial image of the region is annotated with polygons for foraging fields and lines for roads, and an estimated value of resources on those fields are made. As the result, authors obtain a semantically annotated map, which can be used for further automatic evaluation of a specific apiary location. Based on this semantic map, in the second step, chosen location is evaluated using additional levels for pesticides, road effect on the foraging activity. Then the exact number of hives which can be placed in the location is presented. As well several predefined parameters are used for the calculations.

For the final calculation of an optimal number of colonies that should be placed at a specific location chosen by the beekeeper several additional parameters should be introduced.

$$
\text { delta }=h^{*} \mathrm{k}=2 / 5 * 0.35(1)
$$

Where:

$\mathrm{k}$ - honey bees foraging efficiency ( $\mathrm{k}=0.35$ used in example);

$\mathrm{h}$ - nectar to honey production rate ( $\mathrm{h}=0.4$ used in example);

This means that bee colony needs $5 \mathrm{~kg}$ of nectar to produce $2 \mathrm{~kg}$ of honey (Гребенников, 2005), and honey bee foraging efficiency is 35\% (Нарчук and Морева, 2016). Foraging efficiency describes the amount of possible percent of nectar foraging as all nectar could not be foraged. Honey bees are not able to forage all nectar due to the several reasons: part of the nectar will be collected by other insects; bees will not be able to visit all flowers; due to climatic conditions that potentially could be unfavorable.

$\mathrm{H}_{\text {colony }}=90$

For one bee colony approximate $90 \mathrm{~kg}$ of honey is needed for self-consumption (Лебедев and Кривцов, 2019).

$\mathrm{H}_{\text {average }}=60$

Defined amount of honey beekeeper would like to collect from one bee colony. This parameter can be individually defined by the beekeeper.

$$
H(x, y) \geq H_{\text {colony }}(2)
$$

Where: 
128

129

130

131

132

133

134

135

136

137

138

139

140

141

142

143

144

145

146

147

148

149

150

151

152

153

154

155

156

157

158

159

160

161

162

163

164

165

166

167

$\mathrm{H}(\mathrm{x}, \mathrm{y})$ - total potential foraging resources for single colony placed at (x,y);

$\mathrm{H}_{\text {colony }}=$ amount of honey needed for the colony survival

$\mathrm{C}_{1}=$ field nectar productivity coefficient $=\left\{\begin{array}{lllll}0.2 & 0.4 & 0.6 & 0.8 & 1.0\end{array}\right\}$

$\mathrm{C}_{2}=$ field pesticide contamination coefficient $=\left\{\begin{array}{lll}-1.0 & -0.5 & 0\end{array}\right\}$

$\mathrm{C}_{\mathrm{f}}-$ field overall coefficient taking into account the nectar productivity and pesticide contamination

$$
C_{f}=\left\{\text { if } C_{1}+C_{2}>0 \text { then } C_{1}+C_{2} \text { else } 0\right\}(3)
$$

$\mathrm{C}_{3}=$ coefficient for field availability $=\left\{\begin{array}{lll}1 & 0.7 & 0.5\end{array}\right\}$, depending on the road type

$\mathrm{C}_{4}=$ coefficient for the pollution level near roads $\left\{\begin{array}{lll}-0.5 & -0.3-0.1\end{array}\right\}$

Spot $_{1}$ - area of the field segment falling into the area of nectar collection, without taking into account road coefficient

S2 - area of the field segment falling into the area of nectar collection and located near the road (taking into account road coefficient)

$\mathrm{H}(\mathrm{i})$ - amount of nectar foraged from field segment $i$ into the area of nectar collection

$\mathrm{H}_{\text {losses }}(\mathrm{j})$ - the amount of honey losses from field $j$, taking into account areas near roads

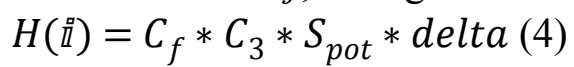

$$
H_{\text {losses }}(j)=C_{f} * C_{3} *\left(-C_{4}\right) * S 2_{j} * \operatorname{delta}(5)
$$

Total nectar collected from the are can be calculated by the formula below:

$$
H=\sum_{i} H(i)-\sum_{J} H_{\text {losses }}(j)(6)
$$

To calculate the number of total colonies that should be placed in the apiary formula below can be used:

Where:

$$
N(x, y)=\frac{H}{\left(H_{\text {colony }}+H_{\text {average }}\right)}(7)
$$

$\mathrm{N}(\mathrm{x}, \mathrm{y})$ - number of colonies placed at a location $(\mathrm{x}, \mathrm{y})$

Proposed model is developed in Python language using several libraries, including Matplotlib for creating static, animated and interactive visualization in Python (Hunter, 2007), NumPy (van der Walt, Colbert and Varoquaux, 2011) and Shapely package for manipulation and analysis of planar geometric objects (Gillies, 2007).

Below the proposed model is described and illustrated in detailed step-by-step process.

\subsection{Getting the map of the target location}

At the first stage it is needed to choose the target location for the apiary and crop the region of interest to work with (see Figure 1a and 1b). Authors used Google Maps for the image selection. Used part of the map can be seen here:

https://www.google.com/maps/@56.4611975,22.9313681,6580m/data=!3m1!1e3 
168 It is assumed that the dimension of the region of interest is $10 \mathrm{~km}$ to $10 \mathrm{~km}$. Region of interest

169

170

171

172

173

174

175

176

177

178

179

180

181

182

183

184

185

186

187

188

189

190

191

192

193

194

195

196

197

198

199

200

201

202

203

204

205

206

207

208

can be also different if needed.

$\mathrm{W}=10000$

where: $\mathrm{W}$ - map region width $(\mathrm{m})$

Fig. 1a. Selected region for the model development

Fig. 1b. Annotated region for the model development

\subsection{Definition of foraging places and roads}

As foraging places agricultural fields are considered at this point. In the future also individual gardens, parks and other locations can be used. Agricultural fields are represented by different polygons and it is needed to mark all of them. At this moment, this task is completed manually using the author's developed web interface.

User should mark all the vertices of each polygon (field) and the tool will extract their coordinates.

In the example, there are 201 polygons defined within the selected region of interest.

$$
\forall f_{n} \in F \rightarrow P_{n}=O\left(f_{n}\right)(8)
$$

where:

$F$ - fields from regions of interest

$\mathrm{P}_{\mathrm{n}}-$ number of polygons

$O(f)$ - polygon outlining the field

In addition, lines which are representing roads (or impossible sources of resources for bees) are defined. The lines are marked manually using the same web interface. User should mark all the end (key) points of each line and the tool will extract their coordinates. In the example, there are 28 lines defined within the selected region.

$$
\forall r_{n} \in R \rightarrow l_{n}=O\left(r_{n}\right)(9)
$$

where:

$\mathrm{R}$ - roads from regions of interest

$\ln$ - number of lines

$\mathrm{O}(\mathrm{r})$ - line representing the road

\subsection{Transforming the real image to semantically annotated map of polygons and lines}

Based on the coordinates generated in the previous stage, the region annotated with chosen polygons and roads is generated (see Figure 2). This region afterwards can be processed in different ways, applying different layers and parameters for the polygons.

Fig. 2a. Generated digitized map of the region of interest with fields

Fig. 2b. Generated digitized map of the region with roads

Peer] reviewing PDF | (2021:04:60588:1:0:NEW 20 Aug 2021) 
209

210

211

212

213

214

215

216

217

218

219

220

221

222

223

224

225

226

227

228

229

230

231

232

233

234

235

236

237

238

239

240

241

242

243

244

245

246

247

248

After the digitized map is built several layers (levels) are introduced to the proposed model.

\subsection{Level 1 - Definition of the nectar production}

Resource availability at the agricultural fields is one of the main parameters for the foraging resource evaluation in the specific geographical location. In the real situation available foraging resources should be related to the theoretical amount of resources available for bee colony forage. It is a very challenging task to evaluate the exact amount of resources available at a foraging location. It is possible to use the information about specific plants and crops and their indices describing pollen and/or nectar production. In the provided example, polygons' values are assigned randomly to demonstrate the calculation method itself, therefore values can be different from the real situation. It is assumed that surrounded fields can have five different foraging coefficients, and those coefficients are related to the nectar production from one hectare. We assume that nectar production is from $20 \mathrm{~kg}$ to $100 \mathrm{~kg}$ and coefficients are from 0.2 to 1.0:

where:

$$
v_{n}=V\left(p_{n}\right)=U \in\{0.2,0.4,0.6,0.8,1.0\}(10)
$$

$\mathrm{V}(\mathrm{p})$ - plant nectar production index in a given field (represented by polygon)

$\mathrm{U}$ - uniform random distribution over a set of values

For better visualization fields are color encoded. Colors are ranging from bright red to bright green. The region with the highest value will have its polygon colored bright green (see Figure 3).

Fig. 3. Encoding of the fields based on a potential nectar production

2.5. Level 2 - Definition of the possible pesticides contamination

One of the main ecological anthropogenic factors which has a negative effect on bee colony vitality is chemical (pesticides, herbicides) treatment of the plants. As a result of those operations bees are foraging and taking to the hive nectar and pollen contaminated with pesticides, which can cause poisoning, decrease the honey bee natural immunity and at the end lead to the death of the whole colony (Frazier et al., 2015). Beekeeping products are also contaminated with toxic substances and can negatively affect human health.

Therefore additional parameter was implemented in the model as a coefficient that represents the potential contamination of the fields.

It is possible to use the information about the frequency of treatment of a particular field with chemicals. This information can be collected from the farmers, or farmers can provide this information using some specific app or web platform. In the provided example, polygons' (fields) values are assigned randomly to demonstrate the calculation method itself. It is assumed that three different field states can be in the selected region. The field can be with a high risk of contamination (coefficient value is equal to -1.0). In that case field productivity is decreased to 0.0 . If contamination coefficient is equal to 0.5 , then productivity rate is decreased to 0.5 . In an 
249

250

251

252

253

254

255

256

257

258

259

260

261

262

263

264

265

266

267

268

269

270

271

272

273

274

275

276

277

278

279

280

281

282

283

284

285

286

287

288

289

ideal situation, when the field is not processed with chemicals, the contamination coefficient is equal to 0.0. Contamination coefficients are defined as follows:

$$
d_{n}=D\left(p_{n}\right)=U \in\{-1.0,-0.5,0.0\}
$$

where:

$\mathrm{D}(\mathrm{p})$ - chemical contamination index in a given field (represented by a polygon) U - uniform random distribution over a set of values

For better visualisation fields are color encoded depending on their pesticides coefficient value, ranging from bright red to bright green, with three colour steps. The region with the zero value (field without pesticides) will have its polygon coloured bright green (see Figure 4).

Fig. 4. Encoding of the potential volume of pesticides in the fields

\subsection{Level 3 - Definition of each road value}

When choosing the apiary place it is needed to consider that proximity of roads has a negative effect on bee colony foraging behaviour. This can be explained by the fact that foraging resources are polluted by the transport emissions and heavy metals. As well bees can die due to the collision with the transport if they fly across the road. Some authors suggest to place the apiaries at least $500 \mathrm{~m}$ from the highways and railways (Соловьева, 2009), if the colony will be used for pollen production, then distance from highways should be more than $1 \mathrm{~km}$ (Аношкина, 2018). Other scientists claim that 20-30 $\mathrm{m}$ is enough (Маннапов et al., 2015). For instance in the Civil Law of Latvia (article 1101, https://likumi.lv/ta/en/en/id/225418-the-civil-law) it is stated that bee colonies may be placed, in rural areas at least fifteen meters, but in cities, towns or villages, at least twenty five meters from traffic routes or the land boundaries of neighbors, such distance being calculated from the center of the hive to the edge of the road or the boundary, and if the apiary is fenced - in rural areas with at least a two meter, but in cities, towns or villages, a two and a half meter high close-set fence or hedge - the bee colonies may be placed without regard to the aforementioned distances.

We propose to classify roads into three groups and assign coefficients based on required distance from the road. Let's assume that minimal distance from the road to apiary is dependent on the road coefficient. Highway with intensive traffic has a coefficient 0.5 (distance to the apiary should be more than $500 \mathrm{~m}$ ). Railroads has the coefficient 0.3 (distance to the apiary should be more than $300 \mathrm{~m}$ ) and the country roads with light traffic have the coefficient 0.1 (distance to the apiary should be more than $100 \mathrm{~m}$ ).

In the provided example, roads' coefficient values are assigned based on the real situation. It is assumed that three different road types are in the selected region.

$$
r_{n}=V\left(l_{n}\right)=R \in\{-0.5,-0.3,-0,1\}(12)
$$

where:

$\mathrm{V}(1)$ - road index (represented by polygon with width)

$\mathrm{R}$ - roads from regions of interest

To visually differentiate roads by their value, color and line width encoding is

implemented, ranging from bright red to bright green, with three color steps. The region with the 
290

291

292

293

294

295

296

297

298

299

300

301

302

303

304

305

306

307

308

309

310

311

312

313

314

315

316

317

318

319

320

321

322

323

324

325

326

327

328

329

330

331

highest value (less harmful, as coefficients with minus sign) will have its line colored bright green (see Figure 5).

Fig. 5. Encoding of the roads on a selected area

In addition, it is considered that crossing the road can increase the probability of bee death affecting bee colony productivity due to decrease of the number of bee foragers. It is needed to define the active polygon, where apiary is located and non-active, which are located across any road (railway, railroad or country road) (see Figure 6).

Fig. 6. Digital map with the active polygon between all roads map (for point with coordinates $(552,364))$

For those polygons potential field productivity is decreased to $70 \%$. Depending on the road type field productivity will be additionally decreased by $20 \%$ for the highway and railroad. Digital map with the polygons between main roads map is demonstrated in Figure 7.

Fig. 7. Digital map with the polygons between main roads

\subsection{Level 4 - Bee colony flight area}

To represent bee colony foraging area, several parameters should be pre-defined, such as target location, expressed as a point coordinate (x,y), and flight area radius (in $\mathrm{km}$ ). The parameters can be user adjusted. This information is defined as a separate layer for the model. As an example, Figure 8 represents a bee colony foraging area at location $(552,364)$ with bee flight radius $3 \mathrm{~km}$ (Prešern et al., 2019).

Fig. 8. Target location of the apiary with the potential bee colony flight radius

\subsection{Layer intersections with the colony flight area}

For the model calculations total areas of regions of intersections with the colony flight area were used. Different layer parameters were taken into account to determine potential production value. Thus for the given example of the apiary location in the point $(552,364)$ only polygons shown in the Figure 9a-9e below are considered and evaluated. If the foraging field is situated within active polygon and it is not needed to cross any roads, then field coefficient is equal to 1 . If a big road should be crossed then coefficient becomes 0.5 .

Fig. 9a. Intersection of bee colony flight area with the field map with the field coefficients Fig. 9b. Intersection of bee colony flight area with the field map taking into account pesticide coefficients

Fig. 9c. Intersection of bee colony flight area with the road layer

Fig. 9d. Intersection of bee colony flight area with the polygon map between all roads displaying an active polygon

Fig. 9e. Intersection of bee colony flight area with the polygon map between only main roads displaying an active polygon 


\subsection{Calculation of a number of colonies to be placed at a specific location $(x, y)$} For the given example the total amount of honey that can be produced in the given location is 7688.84 which means that 51 honey bee colony could be placed in that location. The result can also be written in JSON format and used by other services for further application or comparison between the locations.

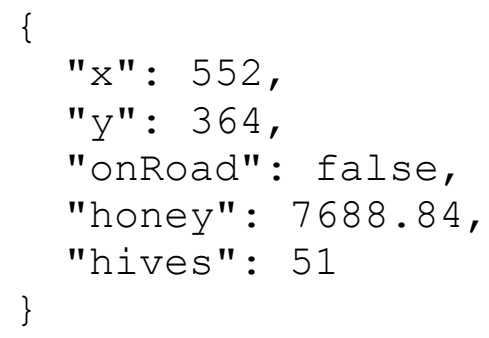

\section{Results and discussion}

Authors presented approach and model for finding the number of honey bee colonies needed for the optimal foraging process in the specific geographical location. Despite the fact that this is actual and important question for the beekeepers there are no many scientific references dealing with this problem and providing different models for such evaluation taking into account various factors and variables. As it was mentioned in the introduction usually beekeepers decide on the amount of the hives based on previous experience without sophisticated analysis of other factors, like availability of foraging resources, presence of nearby roads and other limitations.

There are researches in agricultural pollination which provides guidelines for stocking honey bee colonies in a crop to maximize pollination in the most economical way (Delaplane et al., 2013), but not every beekeeper is using those guidelines.

A less common approach to evaluate the number of colonies is to stock fields with different numbers of colonies and establish whether the rates used have an effect on pollination (PalmerJones and Clinch, 1974; Vaissière, 1991; Brault et al., 1995). But this approach is very rare because it is difficult to obtain acceptably large numbers of replicate fields for each treatment. Some researches show that crop pollination levels appear to be optimal in real-world systems (Pfister et al., 2017) the greater weight of evidence suggests that current pollination levels are usually suboptimal (Garibaldi et al., 2020). This acknowledges the importance and need of some detailed models for the optimal bee colony number evaluation. For all practical purposes, an apiary should normally consist of 30 to 80 colonies, the two most important factors determining the optimum number being the worker population in the hives and the amount of forage available in the area. Where nectar and pollen sources are abundant, an apiary can consist of 50 or more hives with relatively large worker populations without endangering satisfactory yields (Akratanakul, 1990).

Authors presents the model for the evaluation the foraging location and combining it together with real crop nectar production values in the future will provide the valuable tool for the practical beekeepers.

\section{Conclusion}

In this study we propose a computational model that can be used by beekeepers to find the optimal number of hives that should be placed in one apiary location for effective resource foraging process. 
375

376

377

378

379

380

381

382

383

384

385

386

387

388

389

390

391

392

393

394

395

396

397

398

399

400

401

402

403

404

405

406

407

408

409

410

411

412

413

414

415

416

417

418

419

To determine the number of hives in a specific location, the developed model incorporates multiple factors that have a positive and negative effect on foraging - such as the number of fields in the area of interest, field productivity, possible level of contamination (e.g., pesticides), specifics of surroundings, like main roads, railways.

The proposed model is implemented in Python language and potentially can be improved in the future by adding additional levels to better describe the real-life situation/ environment.

As a future work, it is planned to automate the map-to-polygon transformation, to facilitate the user in data pre-processing for the model.

The proposed model requires further evaluation and validation in real world conditions. However, this remains as a challenging task, involving multiple hives, locations and the evaluation of productivity per region.

\section{Acknowledgments}

Hiveopolis project has received funding from the European Union's Horizon 2020 research and innovation programmes under grant agreement No. 824069.

\section{References}

Addi, A. and Bareke, T. 2019. Floral resources diversity of honeybees in important types of vegetation of Ethiopia. Asian Journal of Forestry, 3(2), pp.64-68.

Akratanakul, P., 1990. FAO Agricultural Services Bulletin 68/4: Beekeeping in Asia. Food and Agriculture Organisation of The United Nation. Roma.

Al-Ghamdi, A., Adgaba, N., Getachew, A. \& Tadesse, Y. 2016. "New approach for determination of an optimum honeybee colony's carrying capacity based on productivity and nectar secretion potential of bee forage species". Saudi Journal of Biological Sciences, 23(1), pp.92-100.

Bolshakova, V.L. \& Niño, E.L. 2018. "Bees in the Neighborhood: Best Practices for Urban Beekeepers", 19 pp. doi: 10.3733/ucanr.8596.

Brault, A., De Oliveira, D. and Marceau, J., 1995. Optimization of apple orchard pollination by honey bees in eastern Canada. In Canadian Honey Council Research Symposium Proceedings (Vol. 1995, pp. 55-104).

Delaplane, K.S., Dag, A., Danka, R.G., Freitas, B.M., Garibaldi, L.A., Goodwin, R.M. and Hormaza, J.I., 2013. Standard methods for pollination research with Apis mellifera. Journal of Apicultural Research, 52(4), pp.1-28.

Esteves, R.J.P., Villadelrey, M.C. \& Rabajante, J.F. 2010. "Determining the optimal distribution of bee colony locations to avoid overpopulation using mixed integer programming". Journal of Nature Studies, 9(1), pp.79-82.

Frazier, M.T., Mullin, C.A., Frazier, J.L., Ashcraft, S.A., Leslie, T.W., Mussen, E.C. and Drummond, F.A., 2015. Assessing honey bee (Hymenoptera: Apidae) foraging populations and the potential impact of pesticides on eight US crops. Journal of economic entomology, 108(5), pp.2141-2152.

Free, J. B. (1993). Insect pollination of crops (2nd ed.). London, UK: Academic Press.

Galton, D. 1971. "Survey of a thousand years of beekeeping in Russia". Bee Research Association, London.

Garibaldi, L.A., Sáez, A., Aizen, M.A., Fijen, T. and Bartomeus, I., 2020. Crop pollination management needs flower-visitor monitoring and target values. Journal of Applied Ecology, 
57(4), pp.664-670.

Gillies, S. 2007. "Shapely: manipulation and analysis of geometric objects". Available at: https://github.com/Toblerity/Shapel

Gratzer, K., Susilo, F., Purnomo, D., Fiedler, S. \& Brodschneider, R. 2019. "Challenges for Beekeeping in Indonesia with Autochthonous and Introduced Bees”, Bee World 96(2), pp. 40-44. doi: 10.1080/0005772X.2019.1571211

Hunter, J.D. 2007. "Matplotlib: A 2D Graphics Environment", Computing in Science \& Engineering 9(3), pp. 90-95. doi: 10.1109/MCSE.2007.55

Khanbash, M.S. 2001. "Conservation of Ziziphus trees, from deterioration to raise honey productivity and maintain its quality”. A Study introduced to Fund box to encourage agricultural production and fisheries of the Republic of Yemen, p. 59.

Kohl, P.L. \& Rutschmann, B. 2018. "The neglected bee trees: European beech forests as a home for feral honey bee colonies", Peer J, 2018(4). doi: 10.7717/peerj.4602

Komasilovs, V., Zacepins, A., Kviesis, A., Fiedler, S. \& Kirchner, S. 2019. "Modular sensory hardware and data processing solution for implementation of the precision beekeeping", Agronomy Research 17(2), pp. 509-517. doi: 10.15159/AR.19.038

Komasilova, O., Komasilovs, V., Kviesis, A., Bumanis, N., Mellmann, H. \& Zacepins, A. 2020. "Model for apiary location evaluation", Agronomy Research 18(S2), pp. 1350-1358. https://doi.org/10.15159/AR.20.090

Lázaro, A., Chroni, A., Tscheulin, T., Devalez, J., Matsoukas, C. \& Petanidou, T. 2016. "Electromagnetic radiation of mobile telecommunication antennas affects the abundance and composition of wild pollinators". J. Insect Conserv. 20, 315-324.

Neov, B., Shumkova, R., Palova, N. \& Hristov, P. 2021. "The health crisis in managed honey bees (Apis mellifera). Which factors are involved in this phenomenon?", Biologia, pp.1-8.

Oleksa, A., Gawroński, R. \& Tofilski, A. 2013. "Rural avenues as a refuge for feral honey bee population", Journal of Insect Conservation 17(3), pp. 465-472. doi: 10.1007/s10841-0129528-6

Palmer-Jones, T. and Clinch, P.G., 1974. Observations on the pollination of Chinese gooseberries variety 'Hayward'. New Zealand journal of experimental agriculture, 2(4), pp.455-458.

Pfister, S. C., Eckerter, P. W., Schirmel, J., Cresswell, J. E., \& Entling, M. H. (2017). Sensitivity of commercial pumpkin yield to potential decline among different groups of pollinating bees. Royal Society Open Science, 4, 170102. https://doi.org/10.1098/rsos.170102

Prešern, J., Mihelič, J. and Kobal, M. (2019) 'Growing stock of nectar- and honeydew-producing tree species determines the beekeepers' profit', Forest Ecology and Management, 448, pp. 490-498. doi: 10.1016/j.foreco.2019.06.031.

Vaissière, B.E., 1990, August. Honey bee stocking rate, pollinator visitation, and pollination effectiveness in upland cotton grown for hybrid seed production. In VI International Symposium on Pollination 288 (pp. 359-363).

van der Walt, S., Colbert, S.C. \& Varoquaux, G. 2011. "The NumPy Array: A Structure for Efficient Numerical Computation", Computing in Science \& Engineering 13(2), pp. 22-30. doi: 10.1109/MCSE.2011.37

Visscher, P.K. \& Seeley, T D. 1982. 'Foraging strategy of honeybee colonies in a temperate deciduous forest.', Ecology 63(6), pp. 1790-1801. doi: 10.2307/1940121

Zacepins, A., Brusbardis, V., Meitalovs, J. \& Stalidzans, E. 2015. "Challenges in the 
466 development of Precision Beekeeping", Biosystems Engineering 130, pp. 60-71. doi: 10.1016/j.biosystemseng.2014.12.001.

Аношкина, О.В., 2018. Концепция апимониторинга и оценка экологического состояния месторасположения пасек. In ДОСТИЖЕНИЯ МОЛОДЫХ УЧЕНЫХЗООТЕХНИЧЕСКОЙ НАУКЕ И ПРАКТИКЕ (рp. 302-307).

Гребенников, Е. А. (2005) Все о меде. Минск: Книжный Дом.

Лебедев, В. and Кривцов, Н. (2019) Пчеловодство: разведение и содержание пчелиных семей. Litres.

Маннапов, А.Г., Хоружий, Л.И., Симоганов, Н.А. and Редькова, Л.А., 2015. Технология производства продукции пчеловодства по законам природного стандарта. Монография. " Издательство"" Проспект""'".

Нарчук, Э. П. and Морева, Л. Я. (2016) 'Nectar as a renewable natural resource', Biosfera, $8(3)$, pp. 301-314.

СоЛовьева, Л.Ф., 2009. СОБЛЮДЕНИЕ ВЕТЕРИНАРНО-САНИТАРНЫХ ПРАВИЛ СОДЕРЖАНИЯ ПЧЕЛИНЫХ СЕМЕЙ-ЗАЛОГ ПОЛУЧЕНИЯ ЭКОЛОГИЧЕСКИ ЧИСТЫХ ПРОДУКТОВ ПЧЕЛОВОДСТВА. In Апитерапия сегодня (pp. 205-214). 
Figure 1

Selected region for the model development.

Chosen geographical region, which is used for model development.

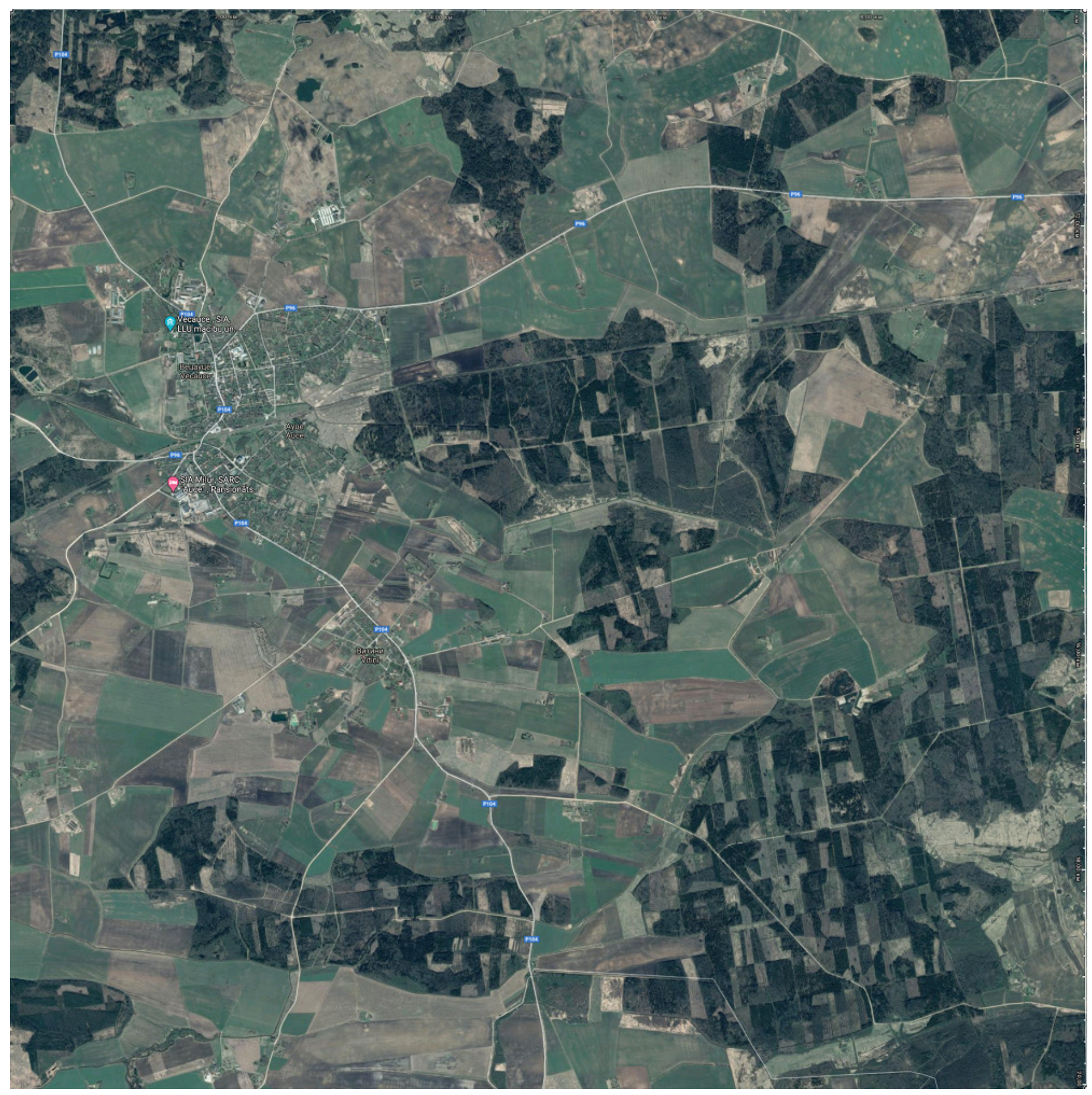


Figure 2

Annotated region for the model development

Annotated geographical region for the model development. Fields and roads are annotated.

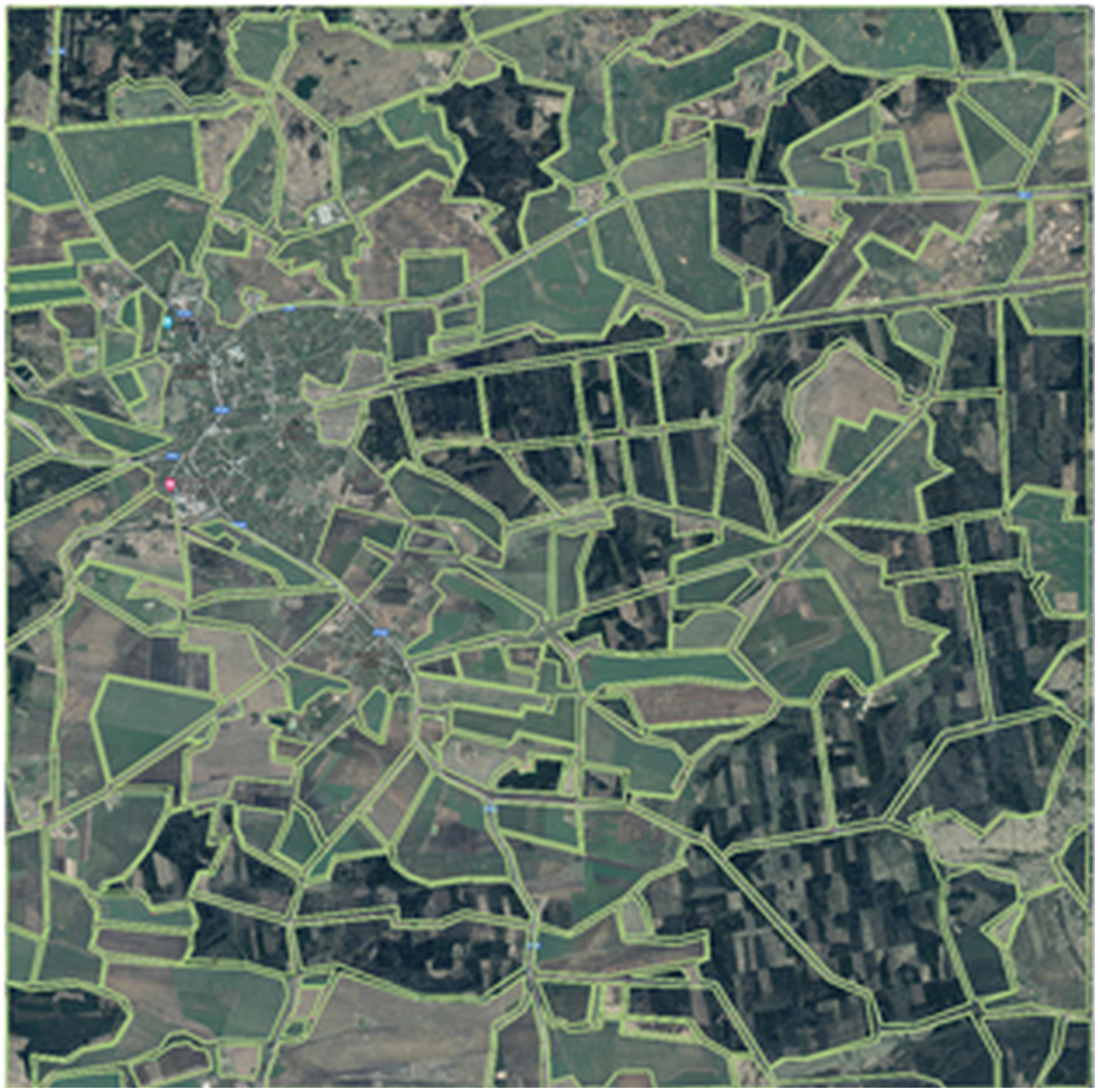


Figure 3

Generated digitized map of the region of interest with fields

Digitized map of the chosen geographical region. All annotated polygons are digitized.

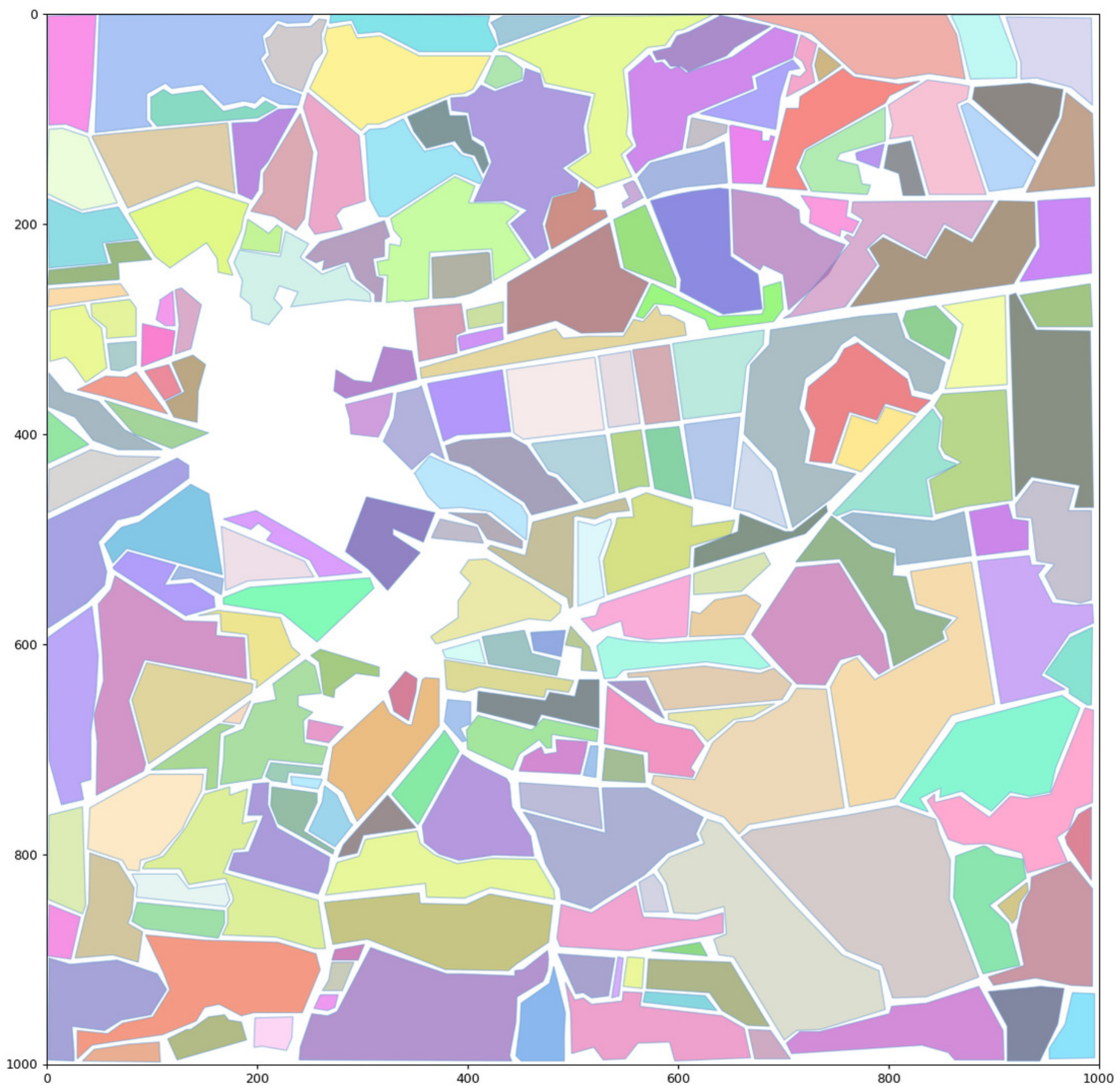


Figure 4

Generated digitized map of the region with roads

Digitized map of the chosen geographical region. All annotated roads are digitized.

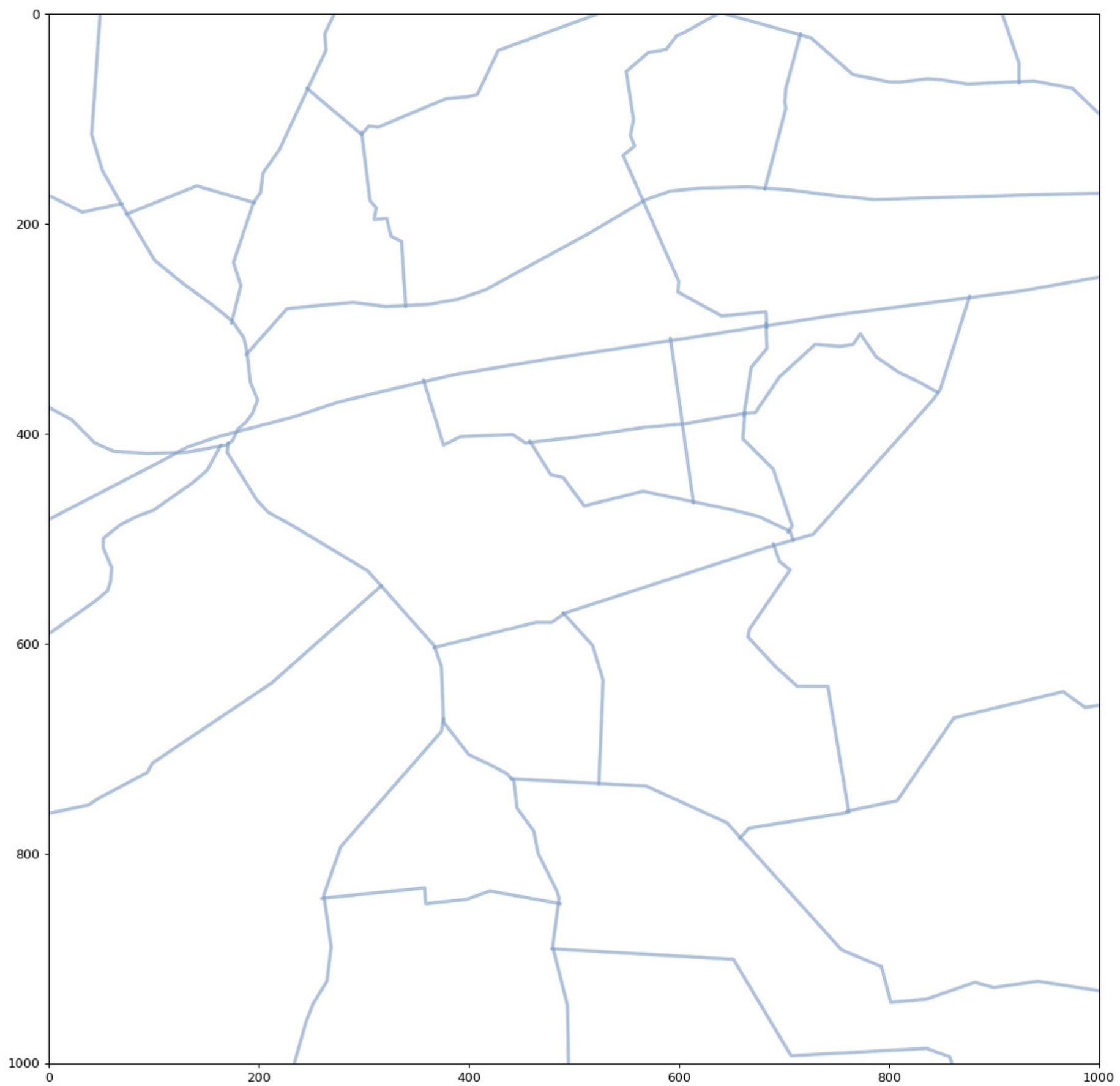


Figure 5

Encoding of the fields based on a potential nectar production

Fields are color encoded. Colors are ranging from bright red to bright green. The region with the highest value will have its polygon colored bright green. 


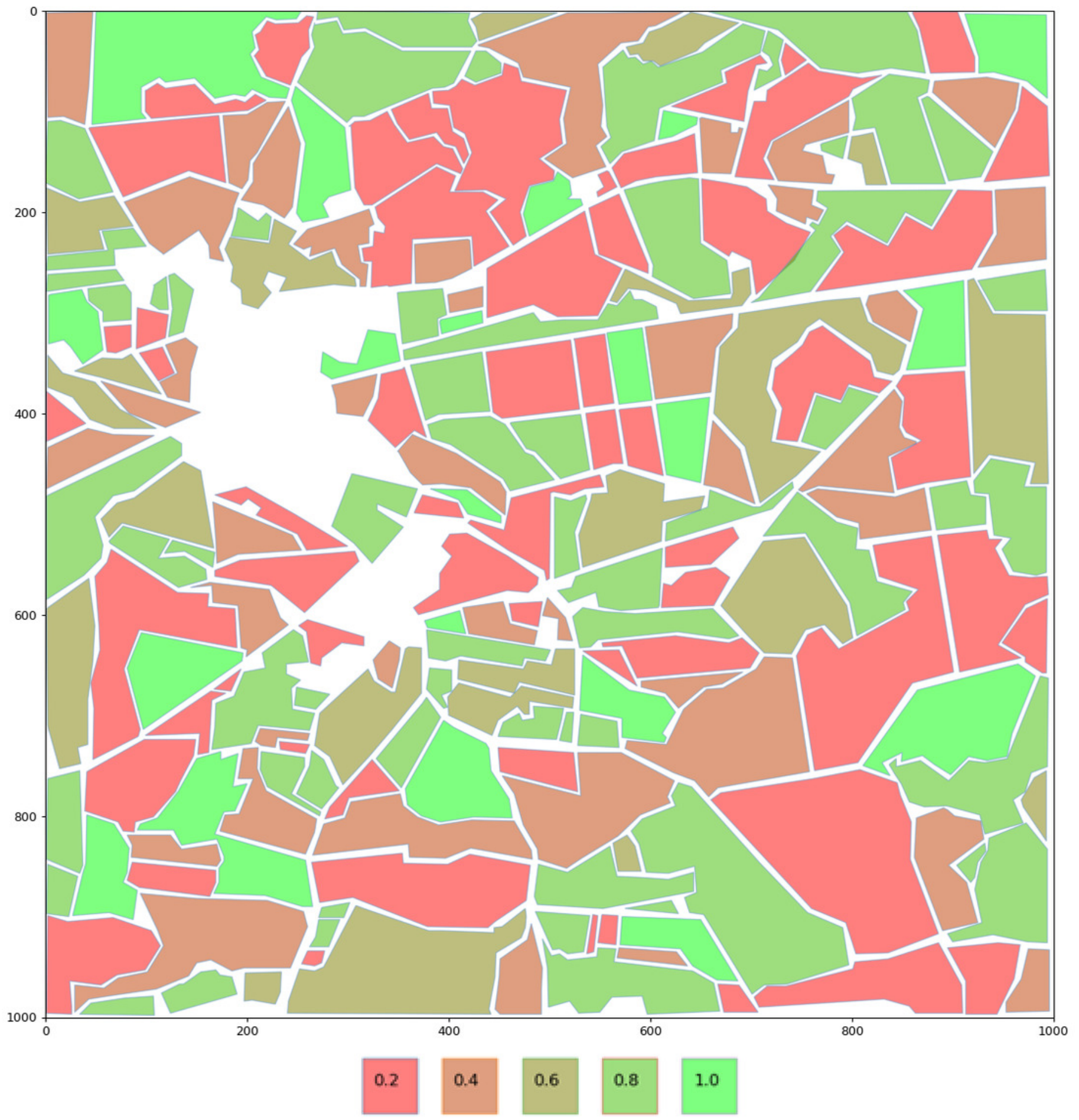


Figure 6

Encoding of the potential volume of pesticides in the fields

Fields are color encoded depending on their pesticides coefficient value, ranging from bright red to bright green, with three colour steps. The region with the zero value (field without pesticides) will have its polygon coloured bright green 


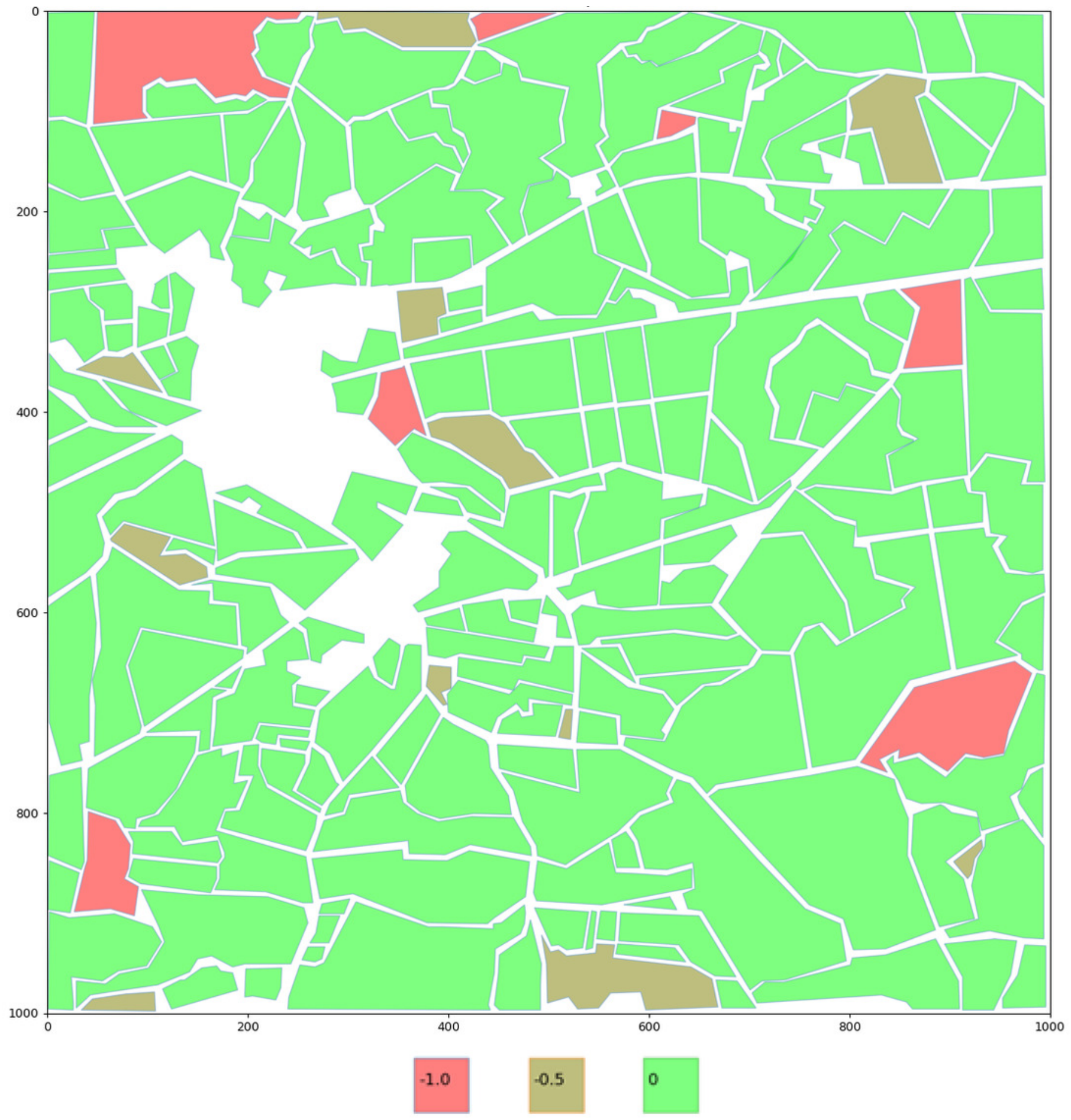


Figure 7

Encoding of the roads on a selected area.

Roads are encoded by their value, color and line width encoding is implemented, ranging from bright red to bright green, with three color steps. The region with the highest value (less harmful, as coefficients with minus sign) will have its line colored bright green. 


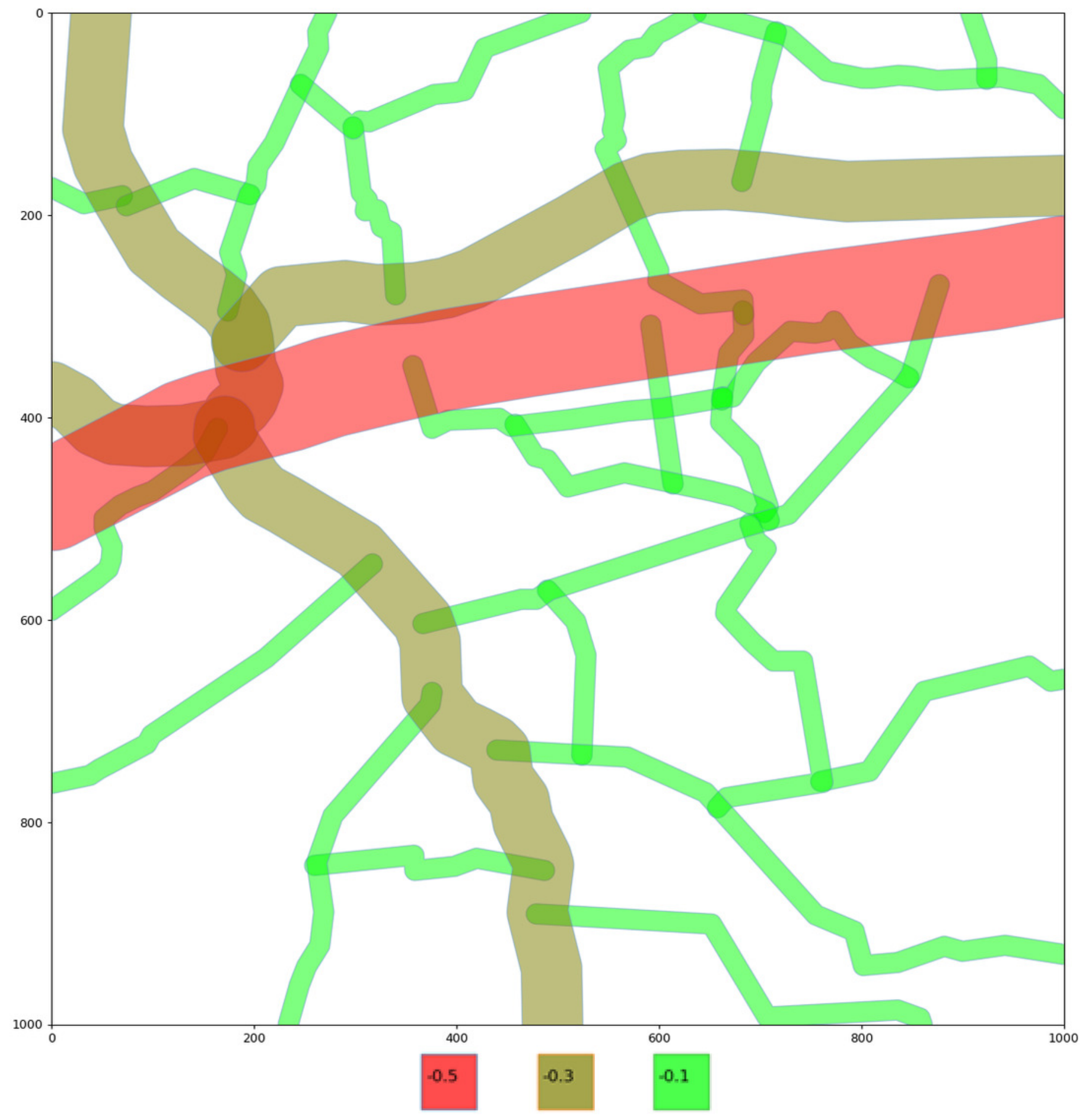


Figure 8

Digital map with the active polygon between all roads map (for point with coordinates $(552,364))$.

Active polygon indicates the location of bee colonies.

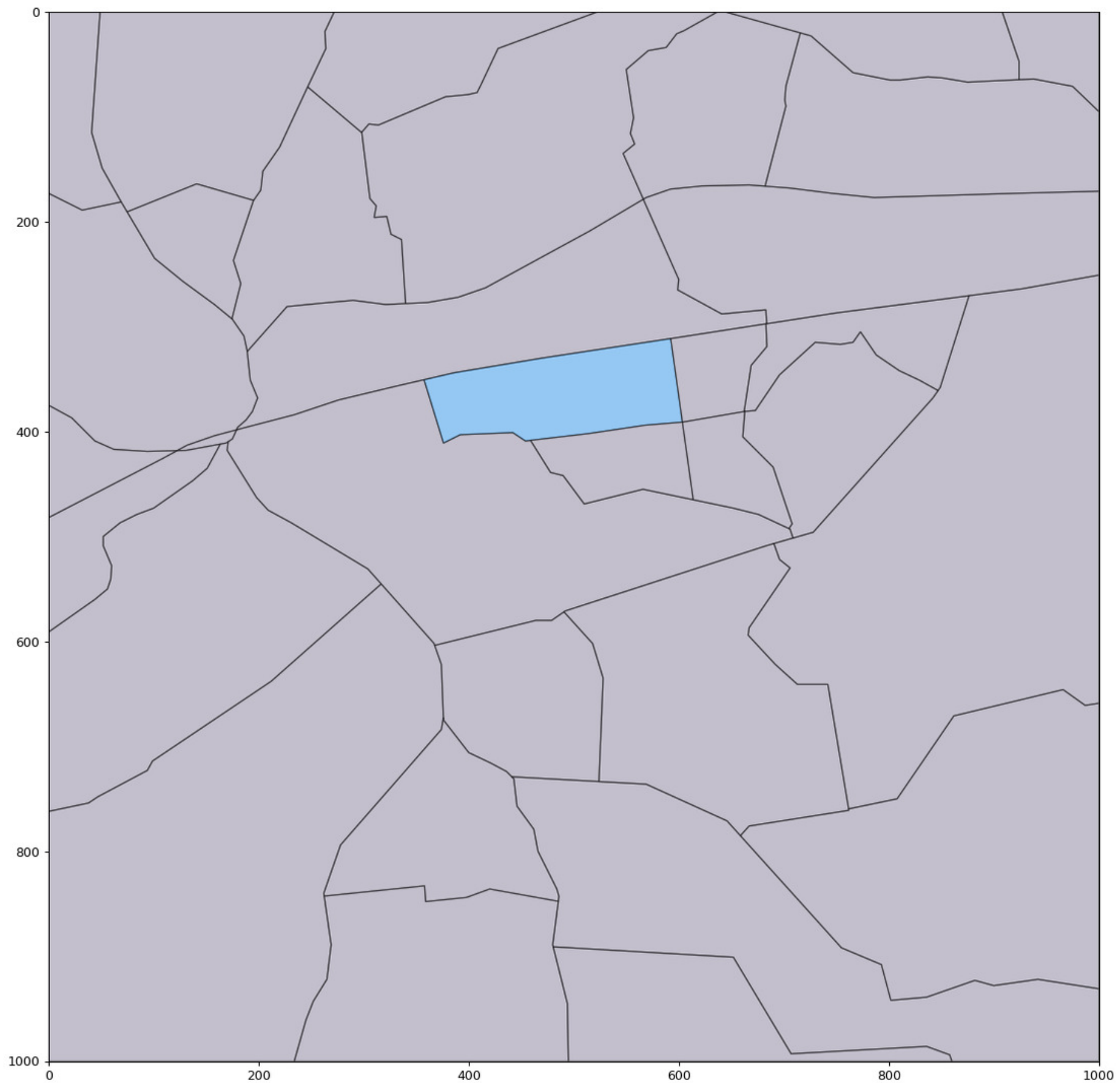


Figure 9

Digital map with the polygons between main roads.

Digital map showing main polygons between main roads.

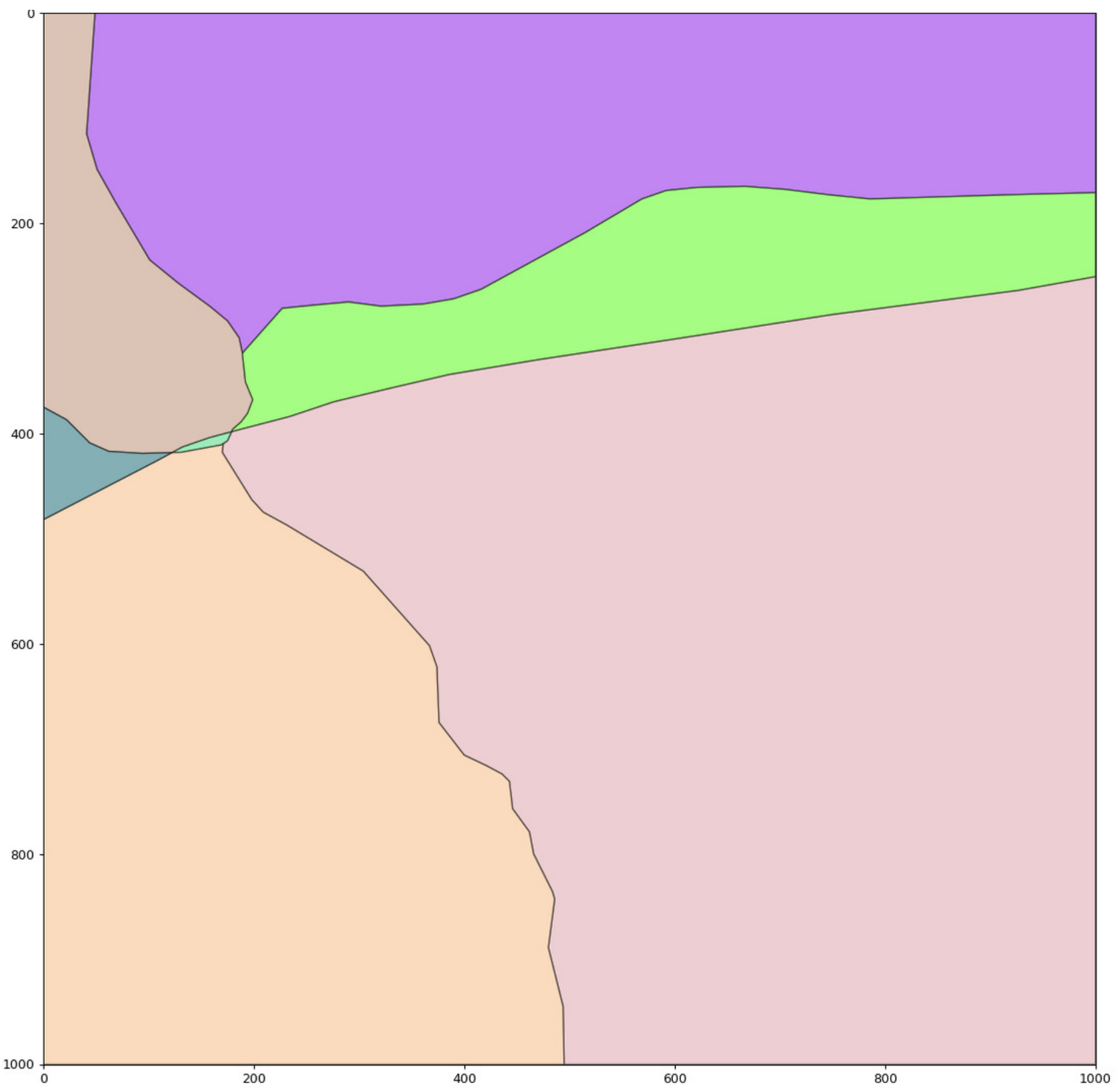




\section{Figure 10}

Target location of the apiary with the potential bee colony flight radius.

Image represents a bee colony foraging area at a specific location (coordinates: 552, 364) with bee flight radius of $3 \mathrm{~km}$. 


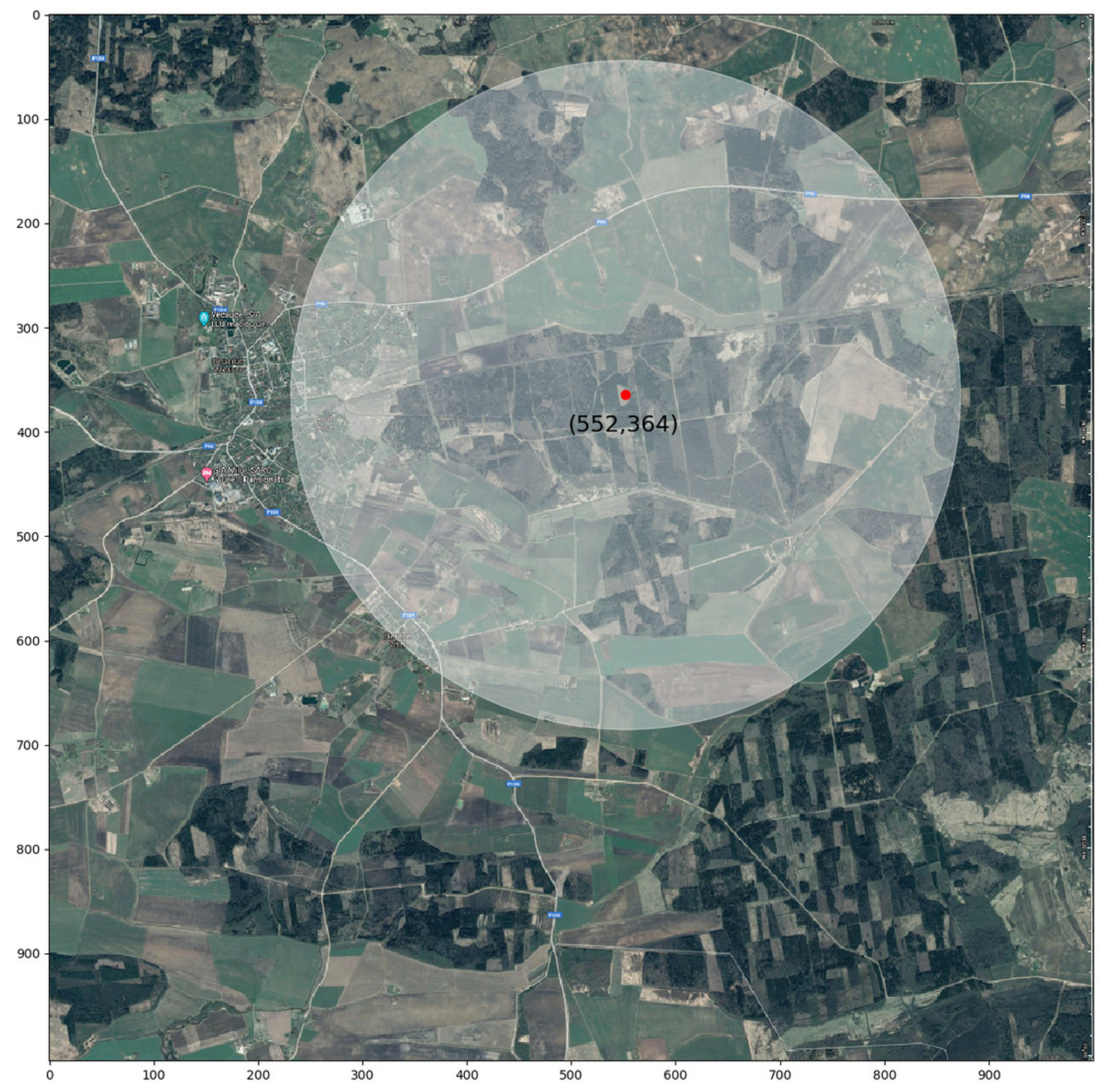




\section{Figure 11}

Intersection of bee colony flight area with the field map with the field coefficients.

Intersection of bee colony flight area with the field map with the field coefficients.

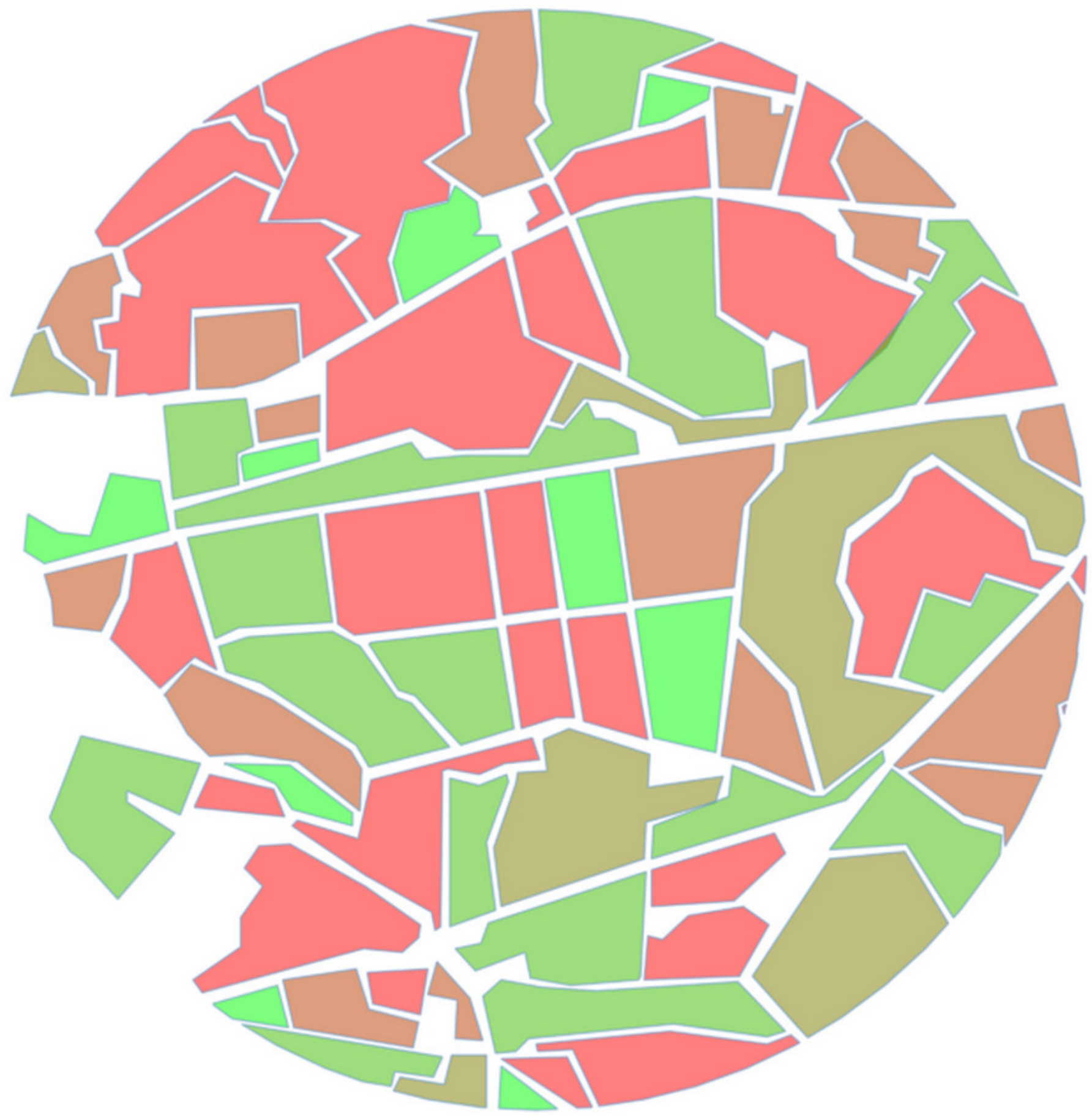


Figure 12

Intersection of bee colony flight area with the field map taking into account pesticide coefficients.

Intersection of bee colony flight area with the field map taking into account pesticide coefficients. 


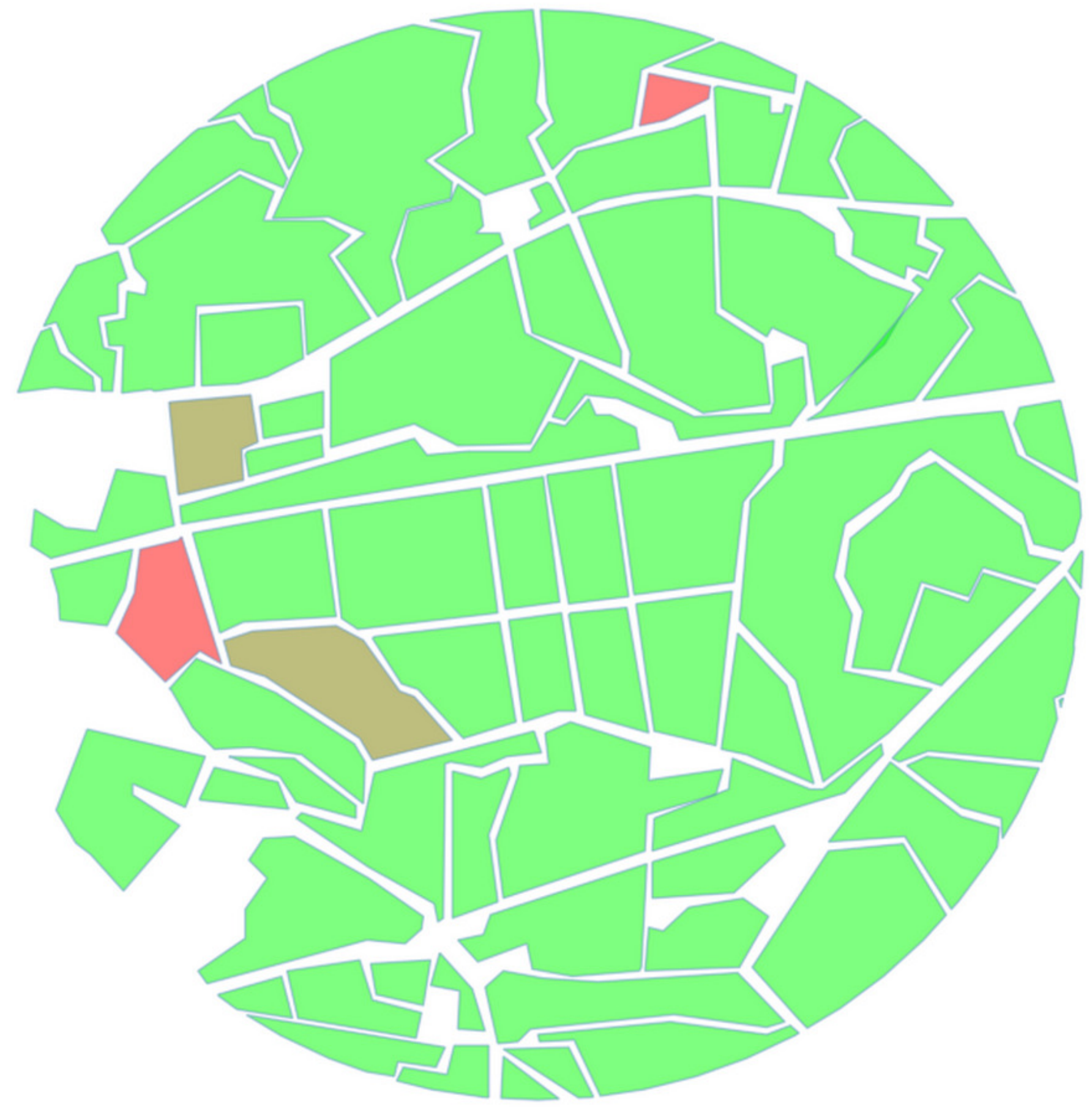




\section{Figure 13}

Intersection of bee colony flight area with the road layer.

Intersection of bee colony flight area with the road layer.

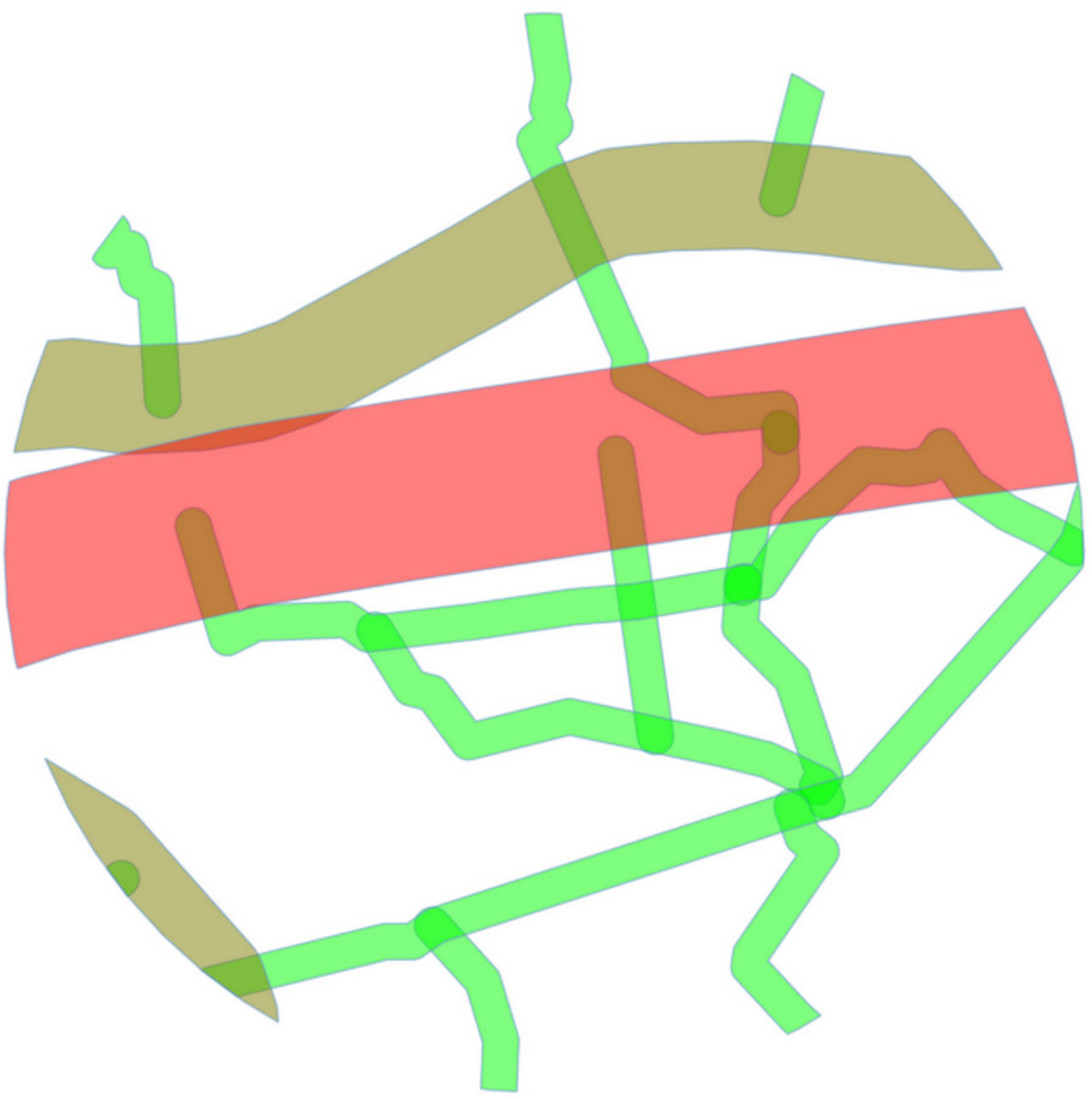


Figure 14

Intersection of bee colony flight area with the polygon map between all roads displaying an active polygon.

Intersection of bee colony flight area with the polygon map between all roads displaying an active polygon. 


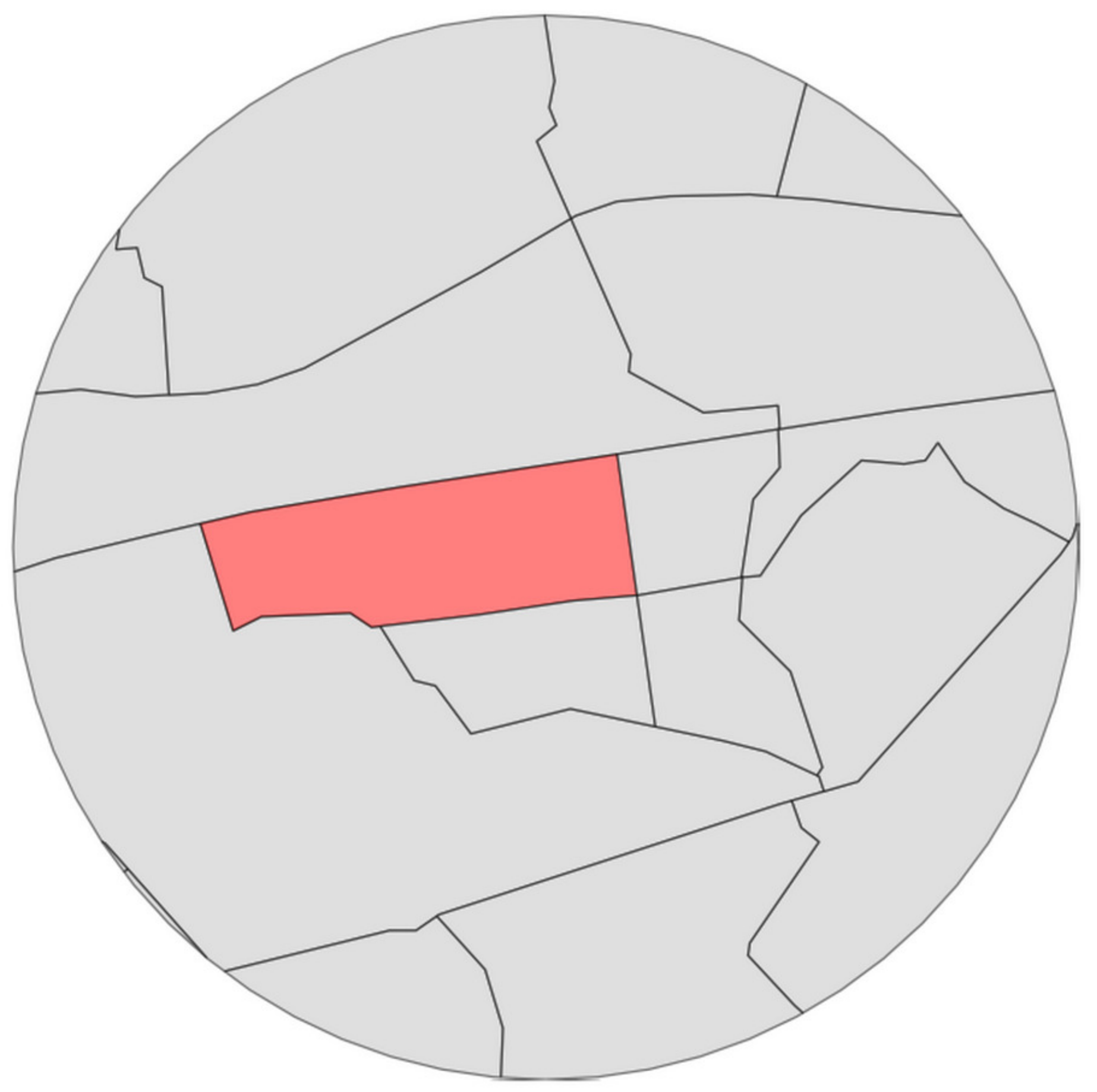




\section{Figure 15}

Intersection of bee colony flight area with the polygon map between only main roads displaying an active polygon.

Intersection of bee colony flight area with the polygon map between only main roads displaying an active polygon. 


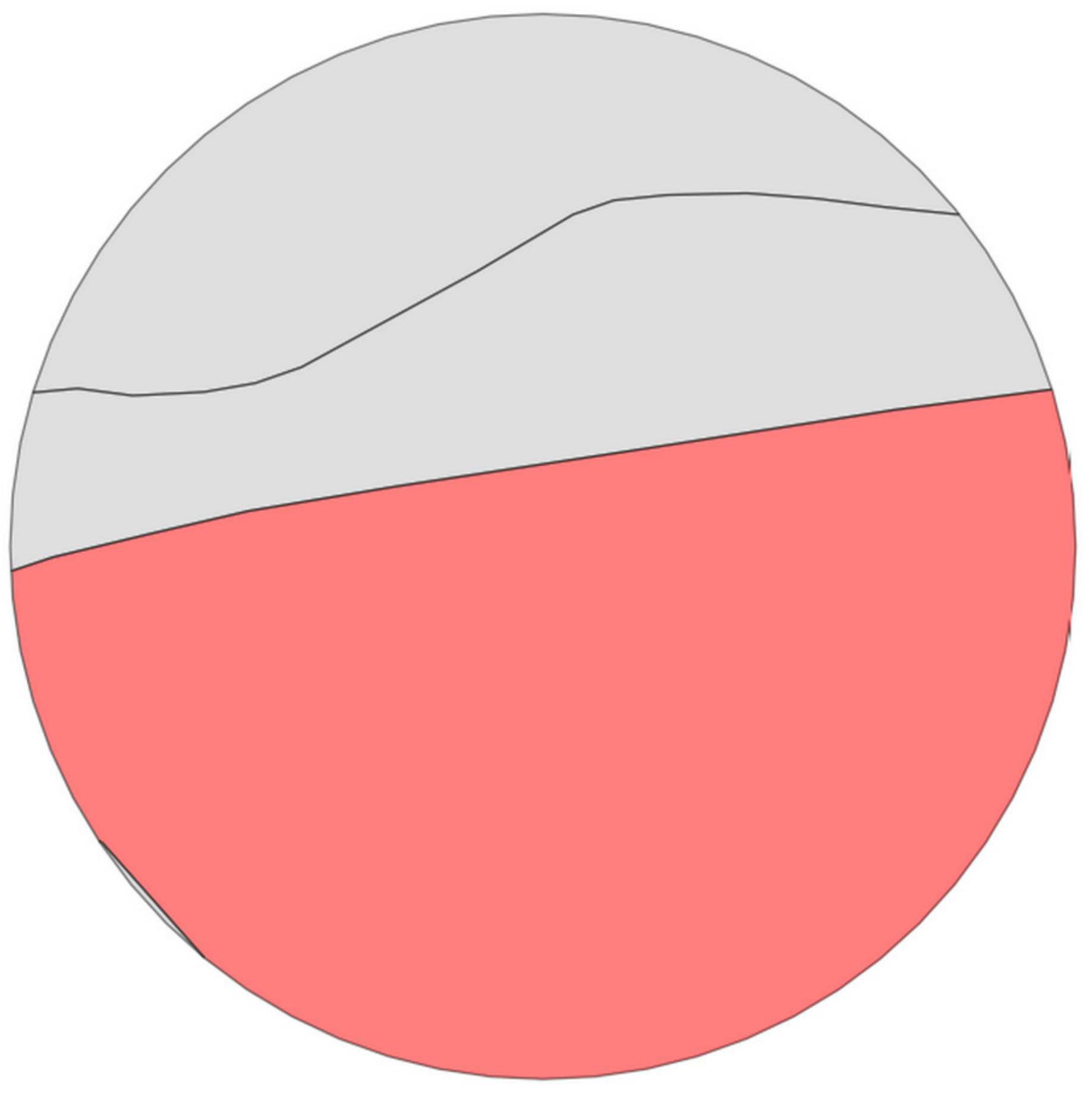

